\title{
DESENVOLVIMENTO INICIAL DE GENÓTIPOS DE FEIJÃO-COMUM SOB CONDIÇÕES DE ALAGAMENTO
}

\section{INITIAL DEVELOPMENT OF COMMON BEANS GENOTYPES UNDER ALAGMENT CONDITIONS}

\author{
Apresentação: Pôster
}

Adrielle Christina Pereira Rocha Santos ${ }^{1}$; Hugo Passos dos Santos $^{2}$; Mickaelle Alves de Sousa Lima ${ }^{3}$; Felipe Ferreira da Silva ${ }^{4}$; Anatércia Ferreira Alves ${ }^{5}$

DOI: https://doi.org/10.31692/2526-7701.IIICOINTERPDVAGRO.2018.00421

\section{Introdução}

O feijão-comum (Phaseolus vulgaris L.) é uma leguminosa herbácea, seu ciclo dura por volta de 95 dias, destaca-se por depender de condições meteorológicas favoráveis, para melhor adaptação e desenvolvimento da cultura, é nítido que o déficit hídrico é um fator limitante para que haja alta produtividade (LOPES et al., 1986).

No Brasil é a principal leguminosa fornecedora de proteínas, fazendo parte da dieta diária das classes socioeconômicas menos favorecidas (ANTUNES et al., 1995). Além das implicações relacionadas à segurança alimentar, a cultura tem notória importância sócio-econômica, haja vista que representa uma importante fonte de emprego e renda no campo.

O aumento da produtividade do feijoeiro no Brasil vem sendo fundamental para o crescimento do setor agrícola nos últimos anos. Para obtenção de produção satisfatória é necessário haver mudanças na eficiência em que os insumos são transformados em produto (USDA, 2008). Para o beneficiamento na produção, devemos destacar os estudos que aprimoram as técnicas, o melhoramento que traz agilidade, precocidade e não deixa a qualidade a desejar.

\footnotetext{
${ }^{1}$ Graduanda em Engenharia Agronômica, UEMASUL, e-mail: adriellecprs@gmail.com

${ }^{2}$ Graduando em Engenharia Agronômica, UEMASUL, e-mail: hugoo.passos@gmail.com

${ }^{3}$ Graduanda em Engenharia Agronômica, UEMASUL, e-mail: mickaellesousalima@gmail.com

${ }^{4}$ Engenheiro Agrônomo, UEMA, e-mail: fsfelipe21@gmail.com

${ }^{5}$ Doutora em Fitotecnia, UFV, e-mail: anaterciaa@yahoo.com.br
} 
O objetivo deste trabalho foi avaliar o efeito do alagamento no desenvolvimento de três genótipos de feijão-comum.

\section{Fundamentação Teórica}

De acordo com Parolin e Junk (2002), o alagamento do solo provoca diminuição do oxigênio sendo um fator limitante ao processo de germinação para grande parte das espécies, especialmente as que se encontram ocupando áreas periodicamente inundadas, como as florestas de várzea da Amazônia. Para superar e conseguir desenvolver-se sob essas condições, as plantas necessitam estabelecer estratégias de tolerância ao alagamento, comprovadas a partir da formação da semente (CARVALHO; NAKAGAWA, 2000).

A deficiência de oxigênio e o baixo potencial redox do solo, induzidos pelo alagamento, afetam desfavoravelmente vários aspectos da fisiologia vegetal, como mudanças na assimilação de carbono, absorção de macronutrientes e supressão do metabolismo respiratório das raízes (KOZLOWSKI, 1997).

Como o feijão é uma planta sensível ao estresse hídrico, por conta da sua baixa habilidade de recuperação após o déficit de água e a um sistema radicular pouco desenvolvido. O estresse causado pelo alagamento do solo pode reduzir a qualidade

fisiológica das sementes, afetando não só a germinação, mas também o desenvolvimento da planta (COSTA et al., 1994).

\section{Metodologia}

O experimento foi conduzido na cidade de Imperatriz, no estado de Maranhão, no Laboratório de Sementes nas dependências da Universidade Estadual da Região Tocantina do Maranhão, no período de agosto a outubro de 2017.

Foram separados 3 genótipos de feijão, BRS MG Talismã, BRS Estilo e Pérola, submersas em copos plástico contendo $100 \mathrm{ml}$ de água destilada, com 20 sementes cada copo, mais o controle (com algodão umedecido com $10 \mathrm{ml}$ de água destilada, contendo também 20 sementes cada um) deixadas na geladeira por um período de 48h. Após esse período de alagamento, os tratamentos foram transferidos para papel germitest, sendo distribuídas as sementes sobre uma linha traçada no terço superior, no sentido longitudinal do papel germitest pré-umedecido. Foram confeccionados rolos semelhantes ao teste de germinação para produzir seis repetições por tratamento. As sementes foram colocadas na B.O.D, com fotoperíodo de 12 horas em claro e 12 horas 
no escuro à temperatura de $25^{\circ} \mathrm{C}$.

Após 10 dias encubadas na B.O.D, foram avaliados os dados de comprimento de raiz $(\mathrm{CR})$ e comprimento do embrião $(\mathrm{CE})$ medido com régua graduada em centímetros, massa fresca (MFE) e massa seca do embrião (MSE) em g/planta, massa fresca (MFC) e massa seca dos cotilédones (MSC) em g/cotilédones. As avaliações foram realizadas a 10 dias após a semeadura. Em seguida foram acondicionadas em sacos de papel e levadas à estufa com circulação de ar a $60^{\circ} \mathrm{C}$ por quatro dias, para avaliação do peso seco de embrião, raiz e cotilédones.

O delineamento experimental foi o inteiramente casualizado, com dois tratamentos (alagado e controle) e seis repetições. As médias foram comparadas através do teste de Tukey a 5\% de significância, realizada com a utilização do programa de estatística SISVAR.

\section{Resultados e Discussões}

No gráfico 1 é apresentado os dados médios de comprimento do embrião dez dias após encubadas na B.O.D. Podemos notar que no geral o genótipo que teve maior crescimento foi o Talismã tanto no tratamento controle como no alagado. Para o tratamento controle não houve diferença estatística nas cultivares Pérola e Estilo, e no tratamento alagado não diferiram os genótipos Talismã e Pérola. Já em relação aos genótipos apenas o Talismã diferiu estatisticamente.

Observando os dados de comprimento da raiz (Gráfico 2), notou-se que a maior raiz no controle foi do Estilo e do Talismã no alagado. Analisando estatisticamente os genótipos, a cultivar Pérola diferiu das demais cultivares no controle e o genótipo Estilo diferiu no alagamento. Quanto ao genótipo todas diferiram estatisticamente. A planta sob estresse hídrico, prioriza o crescimento da raiz para absorver água e perder menos água por transpiração (TAIZ \& ZEIGER, 2009).

Gráfico 1: Dados médios do Comprimento do Embrião, dez dias após encubadas na B.O.D.

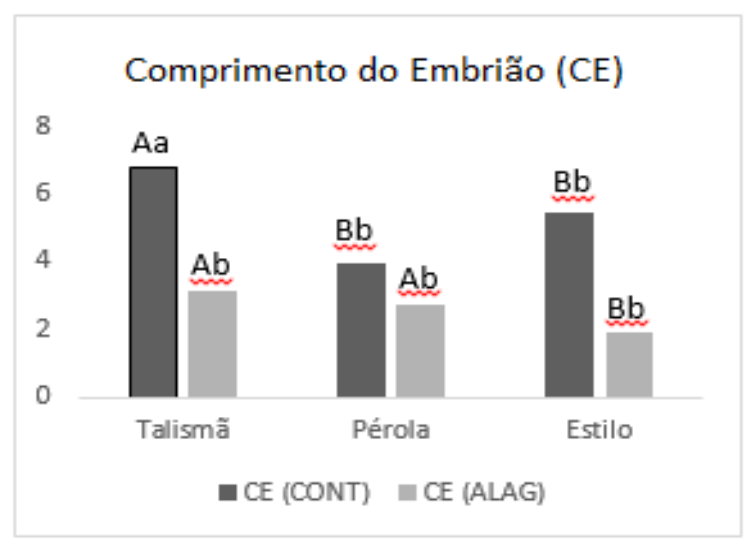

Gráfico 2: Dados médios do Comprimento da Raiz, dez dias após encubadas na B.O.D.

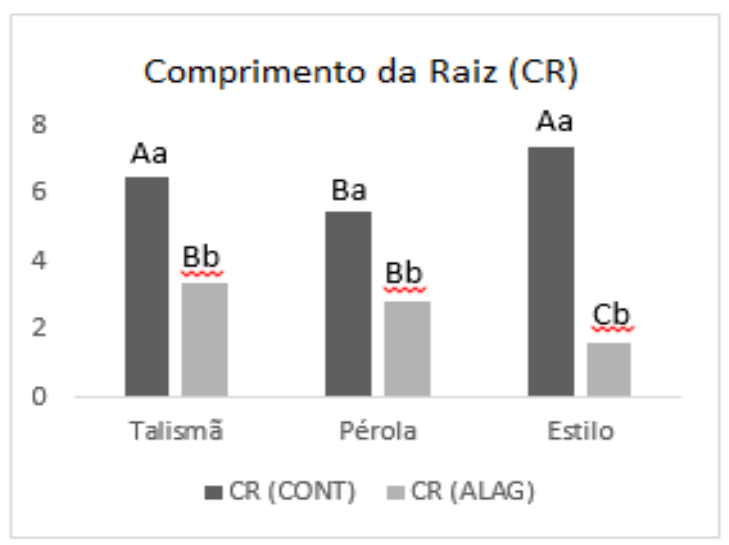


*Letras maiúsculas diferente diferem estatisticamente; letras minúsculas diferentes diferem estatisticamente. Nota: Letras maiúsculas representam, a análise comparativa dos tratamentos; as letras minúsculas representam, a análise comparativa dos genótipos.

De acordo com o gráfico 3, para massa fresca do cotilédone, não houve diferença estatística no tratamento controle e apenas Pérola houve diferença significativa no alagado. Nos genótipos apenas na cultivar Pérola houve diferença.

Para massa fresca do embrião, nos tratamentos teve diferença na cultivar Pérola em relação às demais no controle, e apenas BRS Estilo diferiu no alagamento, e para a análise individual de cada genótipo, todos diferiram (Gráfico 4).

Já na massa fresca da raiz (Gráfico 5), nas cultivares Talismã e Pérola, não possuiu diferença estatística no controle e no alagado somente Pérola diferiu, quanto aos genótipos, todos diferiram. Possivelmente a planta não conseguiu produzir fotoassimilados necessários para manutenção do crescimento da mesma sendo um fator evidenciado com o estresse hídrico (SCALON et al., 2011)

Gráfico 3: Dados médios da Massa Fresca do Cotilédone, dez dias após encubadas na

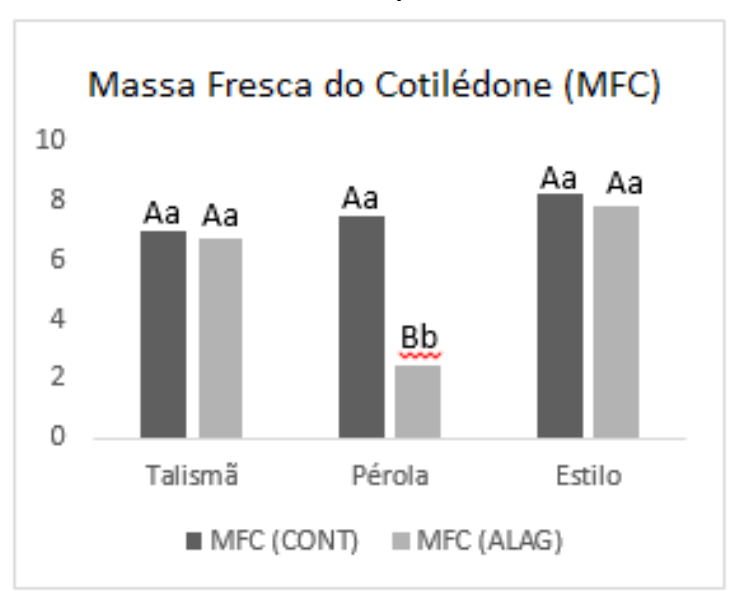

Gráfico 5: Dados médios da Massa Fresca da Raiz, dez dias após encubadas na B.O.D.
Gráfico 4: Dados médios da Massa Fresca do Embrião, dez dias após encubadas na B.O.D.

Massa Fresca do Embrião (MFE)

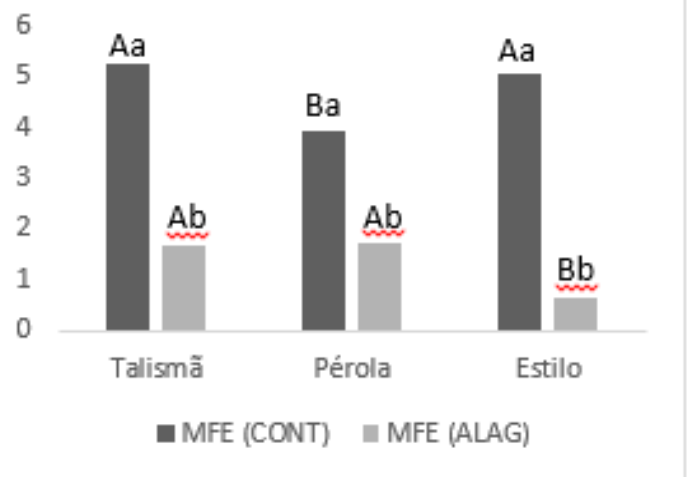




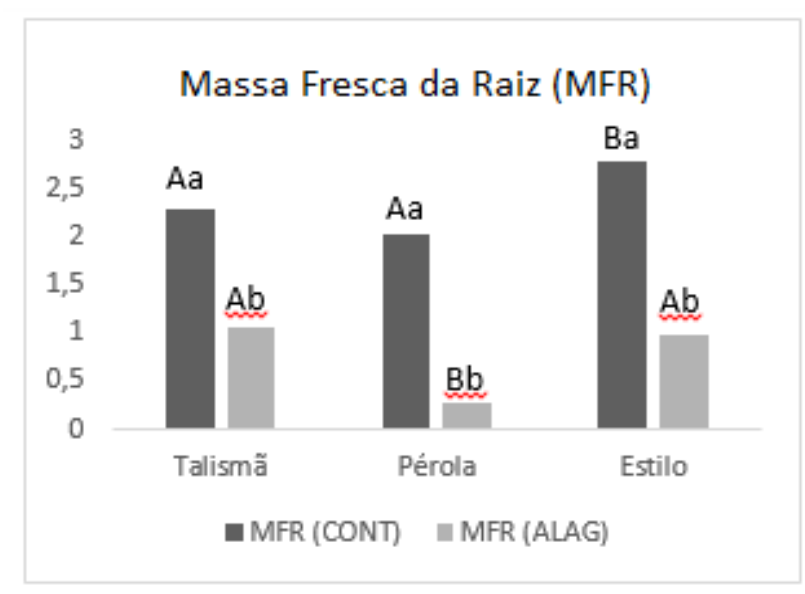

*Letras maiúsculas diferente diferem estatisticamente; letras minúsculas diferentes diferem estatisticamente. Nota: Letras maiúsculas representam, a análise comparativa dos tratamentos; as letras minúsculas representam, a análise comparativa dos genótipos.

Observando a massa seca do cotilédone, compreendeu-se que em nenhum dos tratamentos houve diferença estatística e quanto os genótipos só a cultivar Pérola diferiu (Gráfico 6). Na massa seca do embrião, Pérola diferiu dos demais genótipos no controle, e no alagamento todas diferiram estatisticamente (Gráfico7).

No gráfico 8, apenas Talismã diferiu estatisticamente no controle, e nos genótipos todos diferiram. Quando o ambiente é desfavorável na fase vegetativa, pode ser um empecilho para o desenvolvimento da planta (VERNETTI JUNIOR, 2009).

Gráfico 6: Dados médios da Massa Seca do Cotilédone, dez dias após encubadas na B.O.D.

Massa Seca do Cotilédone (MSC)

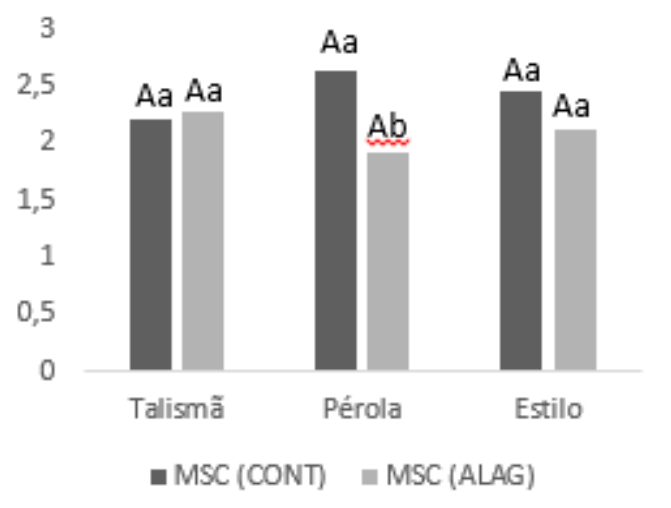

Gráfico 8: Dados médios da Massa Seca da Raiz, dez dias após encubadas na B.O.D.
Gráfico 7: Dados médios da Massa Seca do Embrião, dez dias após encubadas na B.O.D.

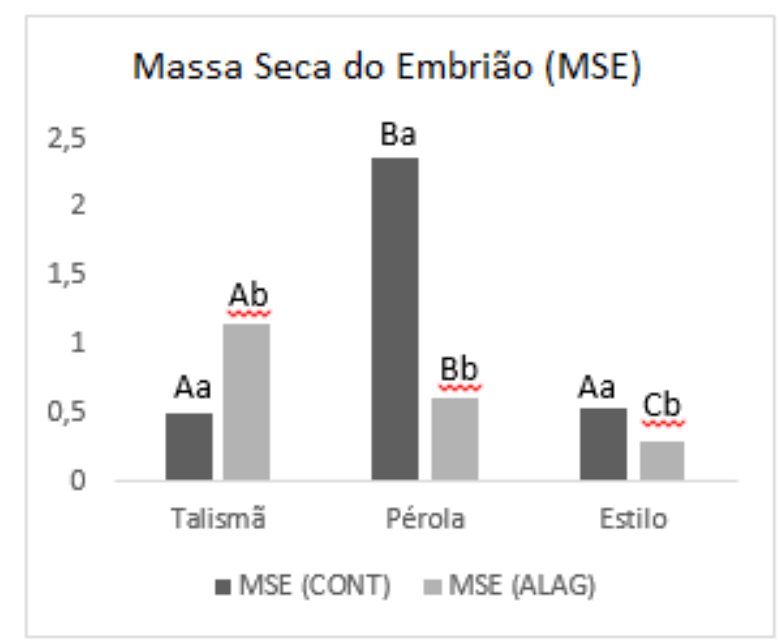




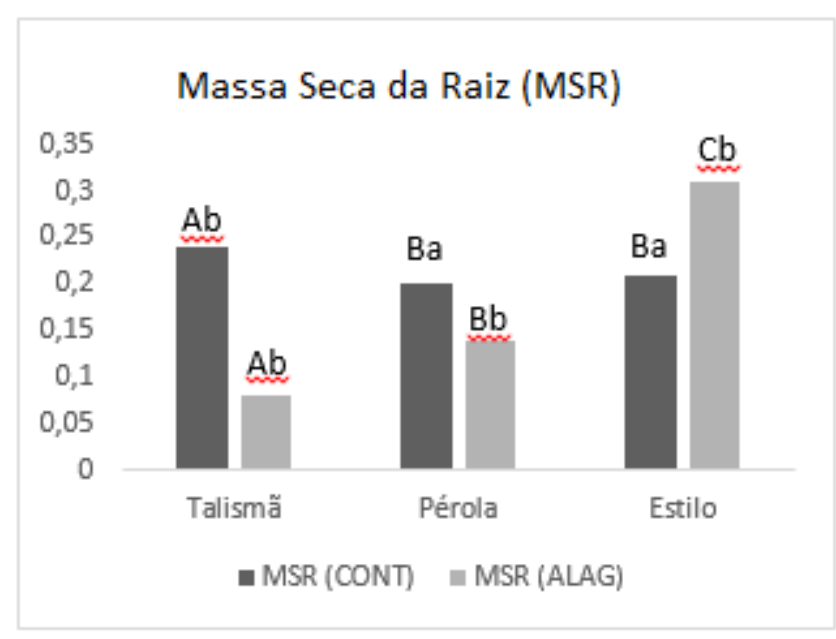

*Letras maiúsculas diferente diferem estatisticamente; letras minúsculas diferentes diferem estatisticamente. Nota: Letras maiúsculas representam, a análise comparativa dos tratamentos; as letras minúsculas representam, a análise comparativa dos genótipos.

\section{Conclusões}

O genótipo BRS MG Talismã consegue maior crescimento sob condições de alagamento, porém a cultivar Pérola mostra-se mais resistente.

O vigor e desenvolvimento dos genótipos BRS MG Talismã, BRS Estilo e Pérola de feijão são afetados negativamente pelo alagamento.

\section{Referências}

ANTUNES, P. L. et al. Valor nutricional de feijão (Phaseolus vulgaris, L.), cultivares rico 23, carioca, piratã-1 e rosinha-g2. Revista Brasileira de Agrociência, Pelotas, v. 1, n. 1, p. 12-18, 1995.

CARVALHO, N.M.; NAKAGAWA, J. Sementes: ciência, tecnologia e produção. 4 ed. Jaboticabal-SP: FUNEP, 2000. 588p.

COSTA, N.P.; PEREIRA, L.A.G.; FRANÇA-NETO, J.B.; HENNING, A.A.; KRZYZANOWSKI, F.C. Zoneamento ecológico do Estado do Paraná para produção de sementes de cultivares precoces de soja. Revista Brasileira de Sementes, v.16, n.1, p.12-19, 1994.

KOZLOWSKI, T. T. Responses of woody plants to flooding and salinity. Tree physiology monograph no. 1. Victoria: Heron Publishing, 1997. p. 1-29.

LOPES, N.F.; OLIVIA, M.A.; CARDOSO, M.J.; GOMES, M.M.S.; SOUZA, V.F. Crescimento e conversão da energia solar em Phaseolus vulgaris L. submetido a três densidades de fluxo radiante e dois regimes hídricos. Revista Ceres, v.33, n.191, p.142164, 1986. 
PAROLIN, P.; JUNK, W.J. 2002. The effect of submergence on seed germination in trees from Amazonian floodplains. Boletim Museu do Museu Paraense Emílio Goeldi. Série Botânica, 18(2): 321-329.

SCALON, S. de P.; MUSSURY, Q. R. M.; EUZÉBIO V. L. DE M.; KODAMA, F. M.; KISSMANN C. Estresse hídrico no metabolismo e crescimento inicial de mudas de mutambo (Guazuma ulmifolia Lam.). Ciência Florestal, v.21, n.4, p.655-662, 2011.

TAIZ, L.; ZEIGER, E. Fisiologia vegetal. 4.ed. Porto Alegre: Artmed, 2009. 819p.

USDA. Department of Agriculture. United States standards for beans. Riverdaile, 2008. Disponível em: \&lt; http://archive.gipsa.usda.gov/referencelibrary/standards/Bean- Standards.pdf\&gt;. Acesso em: 29 dez. 2017.

VERNETTI JUNIOR, F.J. Soja: resultados de pesquisa na Embrapa Clima Temperado - 2009. Pelotas: Embrapa Clima Temperado, 2009. 78 p. (Embrapa Clima Temperado. Documentos, 273). 